\title{
Equipment-related critical incidents in a general intensive care unit
}

\author{
AT King $^{1 *}$, R Wenstone ${ }^{1}$, J Morrison ${ }^{1}$, L Cloherty $^{1}$, ID Welters ${ }^{1,2}$ \\ From ESICM LIVES 2015 \\ Berlin, Germany. 3-7 October 2015
}

\section{Introduction}

The complexity of the care provided for critically ill patients frequently leads to medical errors with potential harm. To improve standards of care, each incident should be recorded, reported and discussed within the team. The reporting system highlights where errors were made and what lessons can be learnt from such incidents. These are commonly reported as "critical incidents" or "serious incidents". A study by Welters et al (2011) found equipment errors accounted for a large number of critical incidents (CI) [1]. It has been found that CIs may lead to longer hospital stays, increasing the cost of patient care; therefore further research into CIs and their prevention is justified [2].

\section{Objectives}

This report investigates the incidence of equipmentrelated incidents within an ICU of a large inner-city hospital. In order to identify the most common equipment related CIs.

\section{Methods}

The data included in this report was collected from a 17 bed ICU of a large inner city hospital, in the North West of England. The data was collected from 20022015. Each CI related to equipment was recorded, and source and mechanism of the error were identified.

\section{Results}

Between July 2002 and February 2015, 564 CIs related to equipment were reported. There were 94 different items of equipment involved in these CIs. Interestingly, CIs relating to use of beds, mattresses and chairs were most common, with 70 (12.41\%) CIs. The other most common pieces of equipment include intravenous infusion pumps $(68,12.05 \%)$, tracheostomies $(51,9.04 \%)$, ventilators $(39,6.91 \%)$, central lines $(32,6.67 \%)$, chest drains $(20,3.55 \%)$, invasive monitoring $(16,2.84 \%)$, renal replacement therapy $(15,2.66 \%)$, bronchoscopy (14, $2.48 \%)$, giving sets $(11,1.95 \%)$, blood gas analysers (11, $1.95 \%)$, and CPAP $(11,1.95 \%)$.

\section{Conclusions}

CI reporting has an important role in any healthcare setting. It allows staff to acknowledge where errors were made, and provides an opportunity to learn from these incidents. By identifying the major sources of equipmentrelated incidents, appropriate training schemes can be developed to avoid such incidents in the future in order to improve patient safety.

\section{Authors' details}

'Royal Liverpool University Hospital, Intensive Care Unit, Liverpool, United Kingdom. ${ }^{2}$ University of Liverpool, Institute of Ageing and Chronic Disease, Liverpool, United Kingdom.

Published: 1 October 2015

References

1. Welters ID, Gibson J, Mogk M, Wenstone R: Major sources of critical incidents in intensive care. Crit Care 2011, 15(5):R232, DOI 10.1186/ cc10474.

2. Kaushal R, Bates DW, Franz C, Soukup JR, Rothschild JM: Costs of adverse events in critical care units. Crit Care Med 2007, 35(11):2479-2483, DOI: 10.1097/01.CCM.0000284510.04248.66.

\section{doi:10.1186/2197-425X-3-S1-A70}

Cite this article as: King et al:: Equipment-related critical incidents in a general intensive care unit. Intensive Care Medicine Experimental 2015 3(Suppl 1):A70. 